\title{
A formação de conceitos em adultos não escolarizados'
}

Delma Barros Filho"

Ana Cecília de Sousa B. Bastos"

\section{Resumo}

Neste trabalho, objetivou-se identificar o nível de abstração presente nos conceitos formulados por adultos não escolarizados que vivem em sociedades letradas. A amostra foi selecionada por conveniência e contou com quarenta adultos não escolarizados (analfabetos e semianalfabetos). Os dados foram coletados por meio da aplicação de instrumento sobre formação de conceitos, e analisados a partir da categorização proposta pelos autores. De acordo com essa categorização, os conceitos podem ser cotidianos ou científicos. Nos conceitos cotidianos, as palavras codificam informações com base nos atributos perceptíveis dos objetos aos quais se referem. Nos conceitos científicos, elas codificam informações com base em aspectos abstratos, não perceptíveis, dos objetos. Para Vigotski, um dos principais objetivos do processo de escolarização é possibilitar a passagem da formulação conceitual cotidiana para a científica. Este estudo investigou a possibilidade de desenvolvimento de uma estrutura conceitual científica fora da escola por adultos não escolarizados que residem em centros urbanos. Os resultados, após a análise das respostas, indicaram que, apesar de alguns desses adultos terem formulado conceitos científicos, predominou em suas respostas um padrão conceitual cotidiano. A partir desses resultados, concluiu-se que, por conta da atual institucionalização, na escola, do treinamento em operações teóricas, o contexto escolar ainda aparece como o mais privilegiado para propiciar esse tipo de desenvolvimento.

\section{Palavras-chave}

I- Parte dos argumentos e dos dados deste Formação de conceitos - Escolarização - Letramento - Escola. artigo integraram a dissertação de mestrado da primeira autora, Formação de conceitos em adultos iletrados: em busca de indícios de oralidade letrada, desenvolvida no programa de pós-graduação em psicologia da Universidade Federal da Bahia, sob orientação da professora Dra. Ana Cecília de Sousa B. Bastos. A pesquisa contou com 0 apoio financeiro da Coordenação de Aperfeiçoamento de Pessoal de Nivel Superior (CAPES).

II- Universidade Federal da Bahia, Salvador, BA, Brasil.

Contato: delmab@gmail.com 


\section{Concept formation by unschooled adults'}

Delma Barros Filho"

Ana Cecília de Sousa B. Bastos"

\section{Abstract}

This article aims to identify the level of abstraction present in the concepts formulated by unschooled adults living in literate societies. The sample was selected by convenience and consisted of forty unschooled illiterate and semi-literate adults. Data were collected by means of tests about concept formation and analyzed according to the categorization proposed by the authors: everyday concepts and scientific concepts. In everyday concepts, words code information based on perceptible attributes of objects. In scientific concepts, words encode information based on abstract, imperceptible aspects of objects. To Vygotsky, one of the main objectives of schooling is the ascension from everyday concepts to scientific concepts. This study aimed to examine the possible development of a scientific conceptual structure outside school by adults who live in urban environments. The results indicated that, although some of these adults formulated scientific concepts, an everyday conceptual standard prevailed in their answers. From these findings, we concluded that, due to the current institutionalization in school of the training in theoretical operations, the school context still appears to be the privileged way of enabling this kind of development.

\section{Keywords}

Concept formation - Schooling - Literacy - School.

I- Master's thesis of the first author Formação de conceitos em adultos iletrados: em busca de indícios de oralidade letrada, Universidade Federal da Bahia. Supervisor: Dr. Ana Cecilia de Sousa B. Bastos. The authors thank Coordenação de Aperfeiçoamento de Pessoal de Nível Superior (CAPES) for their funding.

II- Universidade Federal da Bahia, Salvador,

BA, Brasil.

Contact: delmab@gmail.com 


\section{Introdução}

Diversos estudos que discutem questões relacionadas com o treinamento específico realizado pela escola e seu impacto sobre o desenvolvimento cognitivo têm sido realizados. Brockmeier e Olson (2002), discutindo a disseminação da cultura letrada, destacam que o debate a respeito das relações entre cultura e mente compõe um tema de interesse acadêmico desde, pelo menos, o Iluminismo, sendo que a questão da linguagem e cultura escritas se tornou o foco do debate somente nas últimas décadas do século XX. Atribuem a origem desse interesse a diferentes disciplinas, tais como sociologia, antropologia, história e psicologia, e localizam como ponto inicial de uma das linhas desse debate, em um contexto psicológico, os estudos realizados na década de 1930 por Vigotski e Luria.

Esses trabalhos foram conduzidos por Luria e mais uma equipe em regiões remotas do Uzbequistão e da Kirghizia, em vilarejos e terras de pastoreio localizadas nas montanhas, nos anos de 1931 e 1932, durante a campanha de reestruturação que aconteceu na União Soviética, com vistas a organizar a sociedade em termos do modo de produção socialista. Isso incluiu, na época, eliminar o analfabetismo e promover a transição para uma economia coletivista (LURIA, 1990). Os autores buscaram avaliar os efeitos dessas mudanças sobre as formas de percepção e pensamento (BROCKMEIER; OLSON, 2002; LURIA, 1990; VAN DER VEER; VALSINER, 1996).

Através dessa pesquisa, Vigotski e Luria descreveram algumas das formas de interação entre as mudanças nas circunstâncias culturais e as mentes das pessoas, especificando que os participantes alfabetizados da pesquisa se mostraram mais aptos a pensar de forma abstrata e de maneira autorreflexiva, quando comparados aos participantes não alfabetizados. Indicaram, ainda, não somente que a instituição cultural da escrita permitia às pessoas pensar de forma diferente, em um contexto inteiramente intralinguístico, se fosse necessário, mas também que a escrita e a fala (linguagem oral) são ferramentas centrais da consciência (LURIA, 1990; VIGOTSKI, 2009).

A partir desses trabalhos, iniciou-se um importante campo de estudos, considerando-se o que ficou patenteado como a abordagem de Luria e Vigotski para as dialéticas da alfabetização, do pensamento e da cultura. Vigotski se interessou especialmente pela educação formal, porque compreendia a escola como o contexto capaz de fornecer as condições para o desenvolvimento das modalidades mais complexas de pensamento (LURIA, 1990; VIGOTSKI, 2009).

Com relação à segunda linha do debate, consideram-se os trabalhos desenvolvidos nas décadas de 1960 e 1970 por Michael Cole, Silvia Scribner e colaboradores. Esses autores desenvolveram uma série de estudos transculturais na Libéria (África Ocidental). Dentre esses estudos, destacam-se os conduzidos com o povo Vai. Os pesquisadores compararam os efeitos cognitivos de três formas variadas de alfabetização: uma transmitida informalmente em um sistema de escrita silábica indígena; e outras duas ensinadas formalmente nas escolas, uma em árabe, e a outra em inglês. Entre os Vai, um grande segmento da população não era formalmente educado na escola (BROCKMEIER; OLSON, 2002; VAN DER VEER; VALSINER, 1996).

De acordo com Brockmeier e Olson (2002) - inspirados pelos trabalhos realizados por Luria e Vigotski (LURIA, 1990) -, Michael Cole e Silvia Scribner focaram suas investigações na compreensão do uso do raciocínio lógico pelos participantes da pesquisa, bem como na resolução de problemas e na consciência metalinguística. No entanto, destacam, as conclusões a que Cole e Scribner chegaram foram ligeiramente diferentes daquelas encontradas no estudo pioneiro. Embora tenham reafirmado a influência da escolarização formal sobre algumas modalidades formais de pensamento, contradisseram a hipótese de que o raciocínio lógico seja um efeito direto do fato de se aprender a ler e a escrever. 
Para Cole e Scribner, as habilidades intelectuais dos participantes da pesquisa se mostraram dependentes dos contextos social e prático nos quais as habilidades de leitura e escrita são utilizadas e ensinadas. Os estudiosos passaram, então, a defender uma abordagem mais contextual (situacional-específica) para a relação alfabetização-cultura, em que o desempenho cognitivo de pessoas escolarizadas seja relacionado ao modo particular de discurso desenvolvido através do processo de escolarização formal, ao invés de considerá-lo como consequência do desenvolvimento das habilidades de leitura e escrita (BROCKMEIER; OLSON, 2002).

Desde então, ficaram destacados dois modos principais de considerar a questão: um que opera a fusão entre o conceito de alfabetização e o de cultura, mais afeito, portanto, aos postulados de Cole e Scribner; e outro que separa os efeitos cognitivos do processo de alfabetização e escolarização dos efeitos de outras práticas culturais, aproximando-se da tradição inaugurada por Vigotski e Luria, adotada por Toomela (2003) e seguida no presente trabalho.

Em maior conexão com a proposta de Cole e Scribner, situam-se os trabalhos dos autores da abordagem do letramento. Terzi (2003) propõe o uso do termo letramento de forma disseminada, acoplando o adjetivo crítico quando se refere ao modo de alfabetização que se contrapõe às práticas vigentes no letramento escolar. Esses autores questionam a exclusividade da escolarização formal como via de acesso aos sistemas letrados de conhecimento, apontando que, nas sociedades letradas modernas, o conhecimento pragmático sobre os mecanismos de funcionamento do discurso também se configura como uma possibilidade de desenvolvimento (KLEIMAN, 2001, 2002, 2007; OLIVEIRA, 2003; PEREIRA, 1998; TFOUNI, 2006; VÓVIO, 2007).

Com isso, tais autores colocam em discussão a questão das práticas sociais de desenvolvimento das habilidades de leitura e escrita, chamando a atenção para o papel das atividades sociais mais amplas, que acontecem fora da instituição escolar, as quais efetivamente demandam e ensejam noções aprendidas na escola; seus estudos focalizam especialmente o papel do trabalho. A esse respeito, Pereira (1998) formula a tese de que algumas instituições políticas, entre elas os sindicatos, são efetivas agências de letramento, na medida em que aproximam a oralidade de adultos não alfabetizados da oralidade letrada quanto às suas características argumentativas.

De acordo com as teorizações assumidas no presente trabalho, a oralidade (fala), é considerada uma simbolização de primeira ordem; e a escrita, mais abstrata, uma simbolização de segunda ordem. Assim, a instrução formal transmitida pelo processo de escolarização coloca aqueles que dela participam em condições de se utilizar da escrita em situações substitutivas da língua oral. Adicionalmente, de acordo com as formulações de Vigotski (2009), considera-se que o significado das palavras se modifica, no sentido de que as palavras querem dizer coisas diferentes em distintos estágios do desenvolvimento do pensamento semioticamente mediado. Assim, a maneira como a informação é codificada pode variar, dando origem aos dois tipos mais comuns de estrutura do significado da palavra (ou estrutura conceitual): os chamados conceitos cotidianos e científicos.

A estrutura do significado da palavra (ESP) envolve a descrição do sistema de relações, a maneira como os símbolos são conectados. No pensamento orientado por conceitos cotidianos, as palavras codificam informações com base nos atributos perceptíveis dos objetos aos quais se referem. Nesse caso, os significados da palavra são limitados pelas características e contextos dos referentes externos. Já no pensamento orientado por conceitos científicos, a estrutura dos significados da palavra é abstrata e hierárquica, sua construção é formalmente 
lógica e não depende dos atributos perceptíveis dos objetos (TOOMELA, 2003).

Toomela (2003) propõe que se denomine esses dois modos de utilização da linguagem e esclarece, a partir das formulações dos autores da psicologia histórico-cultural, que esses distintos modos podem ser hierarquizados em níveis, que cada nível obedece a diferentes princípios que determinam os tipos possiveis de relações entre as palavras, estabelecendo possibilidades e restrições.

No presente caso, trata-se do relato de uma pesquisa sobre a organização conceitual de adultos não escolarizados que vivem em sociedades letradas, nas quais o apoio na informação escrita é crucial para a sobrevivência. Para realizá-la, as respostas a testes sobre formação de conceitos foram tomadas como objeto de investigação.

0 objetivo geral deste estudo foi caracterizar, analisar e discutir as relações entre o grau de escolaridade (não alfabetizado, semianalfabeto) e a estrutura conceitual (predominantemente cotidiana ou científica) na amostra de participantes.

\section{Método}

\section{Participantes}

Participaram deste estudo, adultos que preenchiam a condição de ser não alfabetizados ou semianalfabetos. A maioria dos participantes frequentava turmas noturnas de cursos de alfabetização; a outra parte da amostra foi formada por pessoas indicadas por integrantes do grupo no qual a pesquisa foi desenvolvida, sediado no Instituto de Psicologia da Universidade Federal da Bahia. Este estudo contou com quarenta participantes de ambos os sexos. Conforme podemos acompanhar na tabela abaixo, trata-se de uma maioria de mulheres (65\%), com estado civil de solteiras ou em união estável (85\%), e com renda familiar mensal inferior a um salário mínimo (44,7\%). Com relação à escolaridade, o grupo é formado por adultos que não frequentaram a escola ou que, a despeito de tê-la frequentado, permaneceram não alfabetizados (55\%) ou semianalfabetos (45\%).

Tabela 1 - Características sociodemográficas dos participantes $(n=40)$

\begin{tabular}{c|c:c}
\hline Perfil & Categoria & Percentual \\
\hline \multirow{3}{*}{ Sexo } & Feminino & $65 \%(26)$ \\
& Masculino & $35 \%(14)$ \\
\hline \multirow{2}{*}{ Escolaridade } & Não alfabetizado & $55 \%(22)$ \\
& Semianalfabeto & $45 \%(18)$ \\
\hline \multirow{4}{*}{ Estado civil } & Solteiro & $45 \%(18)$ \\
& Casado ou em união estável & $40 \%(16)$ \\
& Divorciado & $2,5 \%(1)$ \\
\hline \multirow{3}{*}{ Renda } & Viúvo & $12,5 \%(5)$ \\
& Menos de 1 sal. mín. & $44,7 \%(17)$ \\
& 1 salário mínimo & $28,9 \%(11)$ \\
\hline & 2 a 3 sal. mínimos & $26,3 \%(10)$ \\
\hline & Valores ausentes & 2 \\
\hline
\end{tabular}

Fonte: Dados da pesquisa

\section{Procedimentos}

Os dados foram coletados em dois tipos de lugares: a) escolas públicas localizadas no estado da Bahia; b) locais combinados previamente com os participantes. Inicialmente, foram fornecidas a cada participante: informações a respeito dos objetivos, justificativa e procedimentos do trabalho; indicações sobre o limite de utilização das informações adquiridas. Além disso, foi-lhes garantida a condição de confidencialidade e liberdade para o conveniente abandono do processo, assegurado pelo caráter da participação voluntária. $\mathrm{Na}$ condução do estudo, foram seguidos os procedimentos éticos estabelecidos no Código de Ética Profissional do Psicólogo (Resoluções N 011/97 e 016/2000, as quais dispõem sobre a realização de pesquisa em psicologia com seres humanos). Uma vez 
aceito o convite, os sujeitos assinaram duas vias do Termo de Consentimento Livre e Esclarecido e forneceram as informaç̃oes solicitadas na Ficha de Dados Sociodemográficos. Em seguida, foi aplicado o Instrumento para Avaliação da Estrutura Conceitual Predominante.

Os testes foram aplicados individualmente. Como os participantes não sabiam ler e escrever, ou o faziam de forma rudimentar, as dezoito perguntas do teste foram lidas pelo aplicador, e as respostas dos participantes, oralmente formuladas, foram anotadas, respeitando-se integralmente sua forma.

\section{Instrumentos}

0 pesquisador preencheu a Ficha de Dados Sociodemográficos com informações dos participantes: idade, estado civil, renda e anos de frequência à escola.

0 Instrumento para Avaliação da Estrutura Conceitual Predominante foi um teste adaptado por Toomela (2003), com base no estudo original de Vigotski e Luria (LURIA, 1990), traduzido para a língua portuguesa por professores que integravam o grupo de pesquisa no qual o presente estudo foi realizado, no Instituto de Psicologia da Universidade Federal da Bahia.

0 instrumento é composto por dezoito questões divididas em três grupos de medidas complementares de identificação da estrutura conceitual: seis questões sobre o terceiro redundante; seis questões sobre detecção de semelhança; e seis questões de definição de conceitos. É formado, portanto, por três grupos de tarefas: terceiro redundante; detecção de semelhança; e definição de conceitos.

$\mathrm{Na}$ tarefa do terceiro redundante, apresentaram-se trios de palavras, um trio por vez, ao participante. A instrução do teste era:

"Nos itens abaixo, de cada três palavras, duas estão interligadas e a terceira palavra é redundante. Por favor, reúna com um círculo as palavras que estão relacionadas e dê uma explicação de por que essas duas palavras se relacionam.”

Alguns exemplos de trios apresentados foram: roda - carro - bicicleta; cenoura sopa - batata.

$\mathrm{Na}$ tarefa de detecção de semelhança, ofereceram-se pares de palavras, um par por vez. 0 enunciado do teste era: "Por favor, responda às questões seguintes. Cite apenas uma semelhança, a mais importante". Entre as questões apresentadas, estavam: "Em que aspecto um gato e um cachorro são semelhantes?"; "Em que aspecto um machado e um martelo são semelhantes?”.

Na tarefa de definição de conceitos, foram explorados conceitos de dois tipos: a) conceitos com os quais as pessoas lidam cotidianamente (com perguntas como "O que é um hospital?" e "0 que é uma escola?”); b) conceitos abstratos (com questões como "0 que é democracia?”; “0 que é reforma social?”).

\section{Critérios para codificação e análise das respostas}

As respostas foram codificadas em duas categorias, com a atribuição do código 0 para as do tipo conceitual cotidiano e com a atribuição do código 1 para as do gênero conceitual científico. Os critérios de análise das respostas seguiram as indicações de Luria (1990) e Toomela (2003).

As respostas do tipo cotidiano foram codificadas como sendo do tipo conceito cotidiano quando a indicação do critério de comunalidade, a descrição da semelhança ou a defınição do conceito fornecido pelo participante foi baseada nos seguintes aspectos: 1) atributos perceptíveis dos objetos, como em "O machado e o martelo são semelhantes porque têm cabos"; 2) observação de atividades cotidianas externas ("Hospital é o lugar que cuida dos doentes"); 3) observação de situações cotidianas e conexão dos objetos em situações cotidianas, que é o caso de "A cenoura se bota na sopa"; 4) descrição da função dos objetos ("É a roda que arrasta o carro"); 5) descrição do compartilhamento de partes, como, por exemplo, em "O gato e 
cachorro são semelhantes porque têm quatro patas"; 6) nenhuma resposta foi fornecida.

A ausência de resposta foi codificada como conceito cotidiano porque alguns itens do teste não são passíveis de resposta quando a estrutura conceitual do participante carece de uma hierarquização ou de conceituação científica. Tal é o caso das respostas às perguntas sobre conceitos abstratos como democracia e reforma social, que não são codificáveis como cotidianas porque ambas requerem uma resposta hierárquica, científica. Assim, quando foi pedido a um participante cuja estrutura conceitual predominante era a cotidiana que respondesse questões dessa natureza, parecia que nada lhe ocorria para dizer. É importante destacar que todos os sujeitos responderam a pelo menos dois itens de cada uma das três partes do teste, o que indica, seguindo as orientações de Toomela (2003), que não se pode atribuir carência de motivação às possíveis ausências de respostas.

Os critérios para a codificação e análise das respostas do tipo conceitual científico foram os seguintes: 1) a relação entre as palavras foi definida hierarquicamente, como, por exemplo, em "O gato e o cachorro são semelhantes porque são mamíferos”; 2) uma palavra é relacionada a um conceito de nível hierarquicamente superior, como em "Democracia é uma forma de legitimação do poder de uma classe ou camada da sociedade sobre as demais, histórica e específica".

Os resultados foram codificados de três maneiras: por dois juízes com discussão em casos de discordância; por um juiz e depois pelo grupo de pesquisa; em reunião do grupo, com leitura das respostas e compartilhamento da codificação.

As informações coletadas através da aplicação deste instrumento passaram por três tipos de tratamento: digitação das respostas no software de processamento de texto Word for Windows; codificação pelos juízes; digitação das respostas codificadas em um banco de dados organizado no software Statistical Package for the Social Sciences (SPSS).

Os dados sociodemográficos dos participantes também foram digitados num banco de dados desse mesmo software.

\section{Resultados e discussão}

Seguindo os parâmetros teóricos adotados, foi estabelecido como critério para a organização dos sujeitos o número de respostas avaliadas como científicas. Sendo assim, apenas os participantes que formularam maior número de conceitos científicos foram considerados na etapa de análise. Essa escolha se justifica, uma vez que se pesquisaram os efeitos atribuídos ao processo de escolarização. Entende-se, portanto, que tais efeitos se expressam de forma mais precisa entre aqueles que exibiram a modalidade de pensamento mais característica da influência escolar.

A partir das respostas científicas, os sujeitos foram divididos em três grupos, conforme modelo de Salomão e Toomela (2010). Tais grupos foram: a) predominantemente cotidiano (em que o participante não forneceu nenhuma ou deu até duas respostas com o tipo conceitual científico); b) misto (em que o participante formulou de três até nove respostas desse tipo); e c) predominantemente científico (quando o participante formulou dez ou mais respostas desse tipo). Conforme já informado, no Instrumento para Avaliação da Estrutura Conceitual Predominante, foram solicitadas dezoito respostas. Sendo assim, cada participante poderia elaborar de nenhuma até dezoito respostas com estrutura científica.

A distribuição dos resultados categorizados como do tipo científico se encontra na Tabela 2. Nenhum dos quarenta participantes da pesquisa formulou todos os dezoito conceitos com estrutura conceitual científica. Os limites mínimo e máximo de conceituação foram, respectivamente, nenhum conceito - resultado obtido por dezoito participantes - e oito conceitos, resultado obtido por um participante. 
Tabela 1 - Características sociodemográficas dos participantes $(n=40)$

\begin{tabular}{c|c|c}
\hline Perfil & Categoria & Percentual \\
\hline \multirow{2}{*}{ Sexo } & Feminino & $65 \%(26)$ \\
& Masculino & $35 \%(14)$ \\
\hline
\end{tabular}

Fonte: dados da pesquisa

Tabela 2 - Distribuição de conceitos científicos $(n=40)$

\begin{tabular}{|c|c|}
\hline Conceitos científicos & Participantes \\
\hline 0 & 18 \\
\hline 1 & 9 \\
\hline 2 & 8 \\
\hline 3 & 2 \\
\hline 4 & 2 \\
\hline 5 & 0 \\
\hline 6 & 0 \\
\hline 7 & 0 \\
\hline 8 & 1 \\
\hline 9 & 0 \\
\hline 10 & 0 \\
\hline 11 & 0 \\
\hline 12 & 0 \\
\hline 13 & 0 \\
\hline 14 & 0 \\
\hline 15 & 0 \\
\hline Total & 40 \\
\hline
\end{tabular}

Fonte: Dados da pesquisa

É possível, ainda, acompanhar que, com exceção de um participante, todos os outros formularam quatro ou menos conceitos científicos. Cinco participantes exibiram uma estrutura conceitual mista.

Apresentados os resultados gerais dos participantes em relação ao número dos conceitos, nos tópicos seguintes, são trazidas análises mais detalhadas. Nelas, são examinadas: as formas de utilização das palavras; os modos como os participantes conectaram os símbolos; e os critérios subjacentes a essa organização. Conforme se disse anteriormente, nas duas primeiras tarefas do instrumento (terceiro redundante e detecção de semelhança), os estímulos oferecidos para a resolução do teste foram palavras em separado; na terceira e última tarefa, foram solicitadas definições de conceitos. A orientação, portanto, seguiu da palavra para o conceito.

\section{Análise dos indícios de oralidade letrada}

Esta seção foi construída visando a identificar se existem indícios de oralidade letrada a partir da maneira como se apresenta a estrutura conceitual nas respostas oralmente formuladas pelos participantes. Para realizar essa discussão, foi operacionalizado um construto que consistiu em considerar que um conceito do tipo científico fornecido oralmente por um participante não escolarizado revela indícios de letramento na fala daquele que o elaborou. Portanto, toda vez que a resposta do participante envolveu o uso do significado da palavra avaliado como do tipo conceitual científico, considerou-se haver tais indícios.

No Quadro 1, estão resumidos os dados sociodemográficos das cinco participantes ${ }^{1}$ que exibiram uma estrutura conceitual classificada como mista.

Quadro 1 - Características sociodemográficas

\begin{tabular}{c:c:c:c:c}
\hline Participante & Sexo & Instrução & $\begin{array}{c}\text { Conceitos } \\
\text { científicos }\end{array}$ & Idade \\
\hline A201 & F & não alfabetizada & $\mathbf{3}$ & $\mathbf{5 1}$ \\
\hline A228 & F & não alfabetizada & 3 & 33 \\
\hline F234 & F & semianalfabeta & $\mathbf{4}$ & $\mathbf{3 5}$ \\
\hline F241 & F & semianalfabeta & 4 & 41 \\
\hline F246 & F & semianalfabeta & $\mathbf{8}$ & $\mathbf{2 1}$ \\
\hline
\end{tabular}

Fonte: Dados da pesquisa

Em relação ao grau de instrução e aos conceitos com estrutura científica formulados, as duas participantes não alfabetizadas elaboraram três desses conceitos; dentre as três participantes semianalfabetas, duas elaboraram quatro conceitos científicos e o outro, oito. Temos, portanto, dois tipos de participantes não escolarizados mistos: a) dois não alfabetizados; e b) três semianalfabetos.

0 modelo de apresentação da análise foi inspirado naquele adotado por Luria (1990). Três dos cinco casos acima (destacados em negrito no Quadro 1) serão analisados, pois essas participantes exemplificam satisfatoriamente

1- Neste momento, passa-se a adotar a forma feminina de participantes no texto porque as cinco são mulheres. 
os modelos para a discussão: uma participante é não alfabetizada e duas são semianalfabetas. Inicialmente, para cada um dos três casos, serão apresentados quadros com as respostas e as análises por conjuntos das dimensões avaliadas: terceiro redundante, detecção de semelhança e definição de conceitos.

\section{Tarefa do terceiro redundante}

Nessa atividade, os trios de palavras que designam objetos podem ser agrupados: a) fazendo-se referência a uma taxonomia, portanto, justificando a reunião das duas palavras com a escolha de uma terceira para representar o par, nesse caso, exibindo estrutura de conceito em maior nível de hierarquia; ou b) explicando a manutenção das duas palavras pela inclusão de ambas em uma situação prática (LURIA, 1990; SALOMÃO; TOOMELA, 2010).

No Quadro 2, constam todas as respostas da primeira participante não alfabetizada. As palavras escolhidas como relacionadas estão sublinhadas. Analisou-se que a resposta fornecida para o segundo trio de palavras possui uma estrutura conceitual do tipo científica.

Quadro 2 - Respostas fornecidas pela participante A201²

\begin{tabular}{|c|c|c|}
\hline $\begin{array}{c}\text { Por que essas duas } \\
\text { palavras se relacionam? }\end{array}$ & Resposta & ECP \\
\hline 1. roda - carro - bicicleta & $\begin{array}{l}\text { Porque o carro tem mais } \\
\text { rodas do que a bicicleta. }\end{array}$ & Cotidiano \\
\hline 2. cenoura - sopa - batata & $\begin{array}{l}\text { Porque ambos são } \\
\text { legumes. }\end{array}$ & Científico \\
\hline 3. piscina - tesoura - salto & $\begin{array}{l}\text { Com o salto se cai na } \\
\text { piscina. }\end{array}$ & Cotidiano \\
\hline 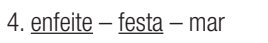 & O enfeite é usado na festa. & Cotidiano \\
\hline 5. janela - porta - chave & $\begin{array}{l}\text { Porque a chave abre a } \\
\text { porta. }\end{array}$ & Cotidiano \\
\hline $\begin{array}{l}\text { 6. } \underline{\text { direção }}-\text { morango } \\
-\underline{\text { passagem }}\end{array}$ & $\begin{array}{l}\text { Porque com a passagem } \\
\text { pegamos o ônibus, que } \\
\text { tem direção. }\end{array}$ & Cotidiano \\
\hline
\end{tabular}

Fonte: Dados da pesquisa

2- Para efeito de simplificação, nos quadros, faz-se referência à estrutura conceitual predominante através da sigla ECP.
A participante excluiu uma das palavras do trio, sopa, seguindo a instrução do teste, e realizou uma operação de síntese ao escolher a palavra legumes para representar as duas outras, cenoura e batata. Mesmo sendo não alfabetizada, a participante operou em um plano teórico, no qual abstraiu as diferenças que existem entre uma batata e uma cenoura e escolheu uma palavra para unificá-las. Trata-se de classificação abstrata, uma vez que selecionou um item e o incluiu em uma categoria taxonômica.

Dando prosseguimento à análise, apresentamos os resultados para o subgrupo de duas participantes semianalfabetas. No Quadro 3 , podemos acompanhar que duas respostas da participante foram classificadas como possuidoras de uma estrutura conceitual científica.

Quadro 3 - Respostas fornecidas pela participante F234

\begin{tabular}{|c|c|c|}
\hline $\begin{array}{l}\text { Por que essas duas } \\
\text { palavras se relacionam? }\end{array}$ & Resposta & ECP \\
\hline 1. roda - carro - bicicleta & $\begin{array}{l}\text { Bicicleta depende da roda } \\
\text { para andar. }\end{array}$ & Cotidiano \\
\hline 2. cenoura - sopa - batata & $\begin{array}{l}\text { Para fazer sopa, tem que } \\
\text { ter legumes e batata é } \\
\text { legume. }\end{array}$ & Cotidiano \\
\hline 3. piscina - tesoura - salto & $\begin{array}{l}\text { Esportista usa a piscina } \\
\text { para fazer saltos. }\end{array}$ & Científico \\
\hline 4. enfeite - festa - $\underline{\text { mar }}$ & $\begin{array}{l}\text { No mar, pode-se fazer um } \\
\text { luau, que é uma festa. }\end{array}$ & Cotidiano \\
\hline 5. janela - porta - chave & $\begin{array}{l}\text { Porta é a proteção da } \\
\text { nossa casa e a chave } \\
\text { completa essa proteção. }\end{array}$ & Científico \\
\hline $\begin{array}{l}\text { 6. direção - morango } \\
\text { - passagem }\end{array}$ & $\begin{array}{l}\text { Passagem de ônibus, } \\
\text { passagem de tempo, os } \\
\text { dois não têm relação. }\end{array}$ & Cotidiano \\
\hline
\end{tabular}

Fonte: Dados da pesquisa

Com relação a esses conceitos, destaca-se inicialmente o que se nomeia aqui como posição de transição. Pelo modo como construiu suas respostas, parece que a participante lida com as palavras de uma maneira mais hierarquizada do que a participante anterior. No nosso entendimento, a participante justificou sua escolha reunindo as duas palavras em situações práticas. Assim, na sentença "Esportista usa a piscina para fazer saltos", ainda que a palavra esportista pareça unifıcar piscina e 
salto, a participante realizou uma tarefa prática, e não teórica, ao indicar que a piscina é utilizada para a realização de saltos, ou seja, fez uma descrição de atividade externa, visual.

0 mesmo tipo de raciocínio guiou a resposta seguinte, em que a palavra proteção, citada duas vezes na sentença "Porta é a proteção da nossa casa e a chave completa essa proteção", parece cumprir o papel de uma categorização taxonômica. Nesse caso específico, ainda que não se desconsidere que o termo proteção possa ter uma conotação abstrata, mais hierárquica em sua utilização, pelo modo como a palavra foi empregada, parece querer indicar estritamente proteção física, concreta, dado que uma casa com proteção completa é aquela cuja porta está trancada pela chave. Por essas considerações, entende-se que se está diante de um momento de maior sofisticação no uso das palavras, relacionado com o formato da sentença, e não com o seu conteúdo.

Como parte final, discutem-se as respostas da participante que formulou o maior número de conceitos classificados como científicos. No Quadro 4, podemos acompanhar suas produções.

Quadro 4 - Respostas fornecidas pela participante F246

\begin{tabular}{|c|c|c|}
\hline $\begin{array}{l}\text { Por que essas duas } \\
\text { palavras se relacionam? }\end{array}$ & Resposta & ECP \\
\hline 1. roda - carro $-\underline{\text { bicicleta }}$ & $\begin{array}{l}\text { Porque os dois } \\
\text { precisam de roda. }\end{array}$ & Cotidiano \\
\hline 2. cenoura - sopa - batata & $\begin{array}{l}\text { Porque são legumes } \\
\text { e os dois vão para } \\
\text { a sopa. }\end{array}$ & Cotidiano \\
\hline 3. piscina - tesoura - salto & Tudo envolve altura. & Cotidiano \\
\hline 4. $\underline{\text { enfeite }}$ - festa - $\underline{\text { mar }}$ & Tudo tem atenção. & Científico \\
\hline 5. janela - porta - chave & Se abrem. & Cotidiano \\
\hline $\begin{array}{l}\text { 6. direção - morango } \\
\text { - passagem }\end{array}$ & $\begin{array}{l}\text { Porque sem } \\
\text { passagem não tem } \\
\text { direção. }\end{array}$ & Cotidiano \\
\hline
\end{tabular}

Fonte: Dados da pesquisa

Para essa tarefa, apenas um conceito foi avaliado como tendo estrutura científica. No segundo trio de palavras, a participante escolheu cenoura e batata e disse que os dois se relacionam porque "vão para a sopa”. Mais uma vez, como fez em relação ao primeiro trio de palavras apresentado, a participante reintroduziu a terceira palavra sem se ater à tarefa proposta, que envolvia retirar um terceiro como redundante. No entanto, ainda que o critério de unificação para as palavras cenoura e batata tenha sido estar juntos na sopa, situação de uso, consideramos que, ao escolher a palavra legumes, a participante categorizou com base em uma palavra, da mesma maneira que a primeira respondente. 0 mesmo aconteceu em relação ao terceiro trio de palavras oferecido, quando foi escolhida a palavra altura. Trata-se de um critério gráfico-funcional de unificação, mas houve uma operação de síntese, do tipo piscina+salto=altura. A resposta seguinte foi classificada como científica: atenção relaciona enfeite e mar.

\section{Tarefa de detecção de semelhança}

Para essa tarefa, foram fornecidas aos participantes duplas de palavras que foram escolhidas com o propósito de averiguar a maneira como eles realizavam as operações de comparação e generalização. Eleger uma base de comparação envolve abstrair diferenças perceptiveis entre os objetos. Luria enfatiza que "Para discernir como dois objetos contrastantes diferem, é necessário apenas descrever seus atributos físicos" (1990, p. 108). No entanto, quando a semelhança entre os objetos não pode ser visualizada, a atividade de comparação e generalização inevitavelmente envolve alguma distinção lógica e linguística.

No Quadro 5, constam todas as respostas da primeira participante. Podemos acompanhar que todas elas foram classificadas como possuidoras de estrutura conceitual do tipo cotidiano. Geneticamente, a capacidade de identificar diferenças se desenvolve antes da possibilidade de eleger uma base comum de comparação entre objetos distintos e indicar uma semelhança (LURIA, 1990).

Com relação à resposta para a semelhança entre motoqueiro e moto, ela foi considerada do tipo cotidiana porque envolve o compartilhamento de partes. 
Quadro 5 - Respostas fornecidas pela participante A201

\begin{tabular}{|c|c|c|}
\hline Em que aspecto... & Resposta & ECP \\
\hline $\begin{array}{l}\text { 1. um gato e um cachorro } \\
\text { são semelhantes? }\end{array}$ & $\begin{array}{l}\text { Porque eles têm quatro } \\
\text { patas. }\end{array}$ & Cotidiano \\
\hline $\begin{array}{l}\text { 2. uma máquina de } \\
\text { escrever e uma caneta são } \\
\text { semelhantes? }\end{array}$ & $\begin{array}{l}\text { Porque eles permitem } \\
\text { escrever. }\end{array}$ & Cotidiano \\
\hline $\begin{array}{l}\text { 3. um motoqueiro e uma } \\
\text { moto são semelhantes? }\end{array}$ & $\begin{array}{l}\text { O nome moto e o nome } \\
\text { motoqueiro lembram um } \\
\text { ao outro. }\end{array}$ & Cotidiano \\
\hline $\begin{array}{l}\text { 4. um machado e um } \\
\text { martelo são semelhantes? }\end{array}$ & Os dois têm cabo. & Cotidiano \\
\hline $\begin{array}{l}\text { 5. a lua e o sol são } \\
\text { semelhantes? }\end{array}$ & Ambos clareiam. & Cotidiano \\
\hline $\begin{array}{l}\text { 6. uma cabeça e um } \\
\text { chapéu são semelhantes? }\end{array}$ & $\begin{array}{l}\text { O chapéu tem o formato } \\
\text { da cabeça. }\end{array}$ & Cotidiano \\
\hline
\end{tabular}

Fonte: Dados da pesquisa

A partir desse ponto, iniciou-se a análise das produções das duas participantes semianalfabetas. No Quadro 6, estão as respostas da primeira delas, em relação às quais se destaca em negrito a que foi avaliada como científica.

Quadro 6 - Respostas fornecidas pela participante F234

\begin{tabular}{|c|c|c|}
\hline Em que aspecto... & Resposta & ECP \\
\hline $\begin{array}{l}\text { 1. um gato e um } \\
\text { cachorro } \\
\text { semelhantes? }\end{array}$ & $\begin{array}{l}\text { Além da vida e de ser } \\
\text { animais não têm nada } \\
\text { em comum. }\end{array}$ & Científico \\
\hline $\begin{array}{l}\text { 2. uma máquina de } \\
\text { escrever e uma caneta } \\
\text { são semelhantes? }\end{array}$ & Ambos escrevem. & Cotidiano \\
\hline $\begin{array}{l}\text { 3. um motoqueiro } \\
\text { e uma moto são } \\
\text { semelhantes? }\end{array}$ & $\begin{array}{l}\text { Um precisa do outro pra } \\
\text { andar. }\end{array}$ & Cotidiano \\
\hline $\begin{array}{l}\text { 4. um machado } \\
\text { e um martelo são } \\
\text { semelhantes? }\end{array}$ & Um racha e o outro prega. & Cotidiano \\
\hline $\begin{array}{l}\text { 5. a lua e o sol são } \\
\text { semelhantes? }\end{array}$ & $\begin{array}{l}\text { Ambos iluminam a terra, um } \\
\text { pelo dia e outro pela noite. }\end{array}$ & Cotidiano \\
\hline $\begin{array}{l}\text { 6. uma cabeça e } \\
\text { um chapéu são } \\
\text { semelhantes? }\end{array}$ & $\begin{array}{l}\text { Para usar chapéu tem que } \\
\text { ter uma cabeça. }\end{array}$ & Cotidiano \\
\hline
\end{tabular}

Fonte: Dados da pesquisa

A participante respondeu que, além do fato de gato e cachorro terem vida, e de serem animais, não têm mais nada em comum. A participante não reconhece como critério de comunalidade aspectos visuais, externamente perceptíveis como: possuir pelos e ter quatro patas, por exemplo, características bastante citadas por todos os participantes. Portanto, localizou-se uma transição no significado da palavra dessa primeira participante. Os outros critérios para eleger semelhanças foram todos apoiados em semelhança visual, função, e inclusão em situações práticas da vida cotidiana.

Por fim, no Quadro 7, constam as respostas da segunda participante desse subgrupo. Duas delas foram avaliadas como possuidoras de estrutura conceitual científica. As análises feitas para as respostas dessa participante se encaixam nas explicações já fornecidas.

Quadro 7 - Respostas fornecidas pela participante F246

\begin{tabular}{|c|c|c|}
\hline Em que aspecto... & Resposta & ECP \\
\hline $\begin{array}{l}\text { 1. um gato e um cachorro } \\
\text { são semelhantes? }\end{array}$ & São seres vivos. & Científico \\
\hline $\begin{array}{l}\text { 2. uma máquina de } \\
\text { escrever e uma caneta } \\
\text { são semelhantes? }\end{array}$ & $\begin{array}{l}\text { É uma forma } \\
\text { de comunicar } \\
\text { e de transmitir } \\
\text { informação. }\end{array}$ & Científico \\
\hline $\begin{array}{l}\text { 3. um motoqueiro e uma } \\
\text { moto são semelhantes? }\end{array}$ & $\begin{array}{l}\text { Os dois precisam de } \\
\text { combustível: moto de } \\
\text { gasolina e o motoqueiro } \\
\text { no uso da água. }\end{array}$ & Cotidiano \\
\hline $\begin{array}{l}\text { 4. um machado e um } \\
\text { martelo são semelhantes? }\end{array}$ & No cabo. & Cotidiano \\
\hline $\begin{array}{l}\text { 5. a lua e o sol são } \\
\text { semelhantes? }\end{array}$ & $\begin{array}{l}\text { Iluminam a terra, o sol } \\
\text { de dia e a lua de noite. }\end{array}$ & Cotidiano \\
\hline $\begin{array}{l}\text { 6. uma cabeça e um } \\
\text { chapéu são semelhantes? }\end{array}$ & Têm o mesmo formato. & Cotidiano \\
\hline
\end{tabular}

Fonte: Dados da pesquisa

\section{Tarefa de definição de conceitos}

Como último ponto dessa análise, discutiremos o conjunto das respostas das três participantes à tarefa de definição de conceitos. Nos termos aqui propostos, definir um conceito envolve incluir um objeto em uma categoria supraordenada, em relação à qual constam elementos cujos atributos singulares foram abstraídos: "Uma pessoa que define uma macieira como árvore, e um bode como 
animal, desconsidera os atributos peculiares à macieira e ao bode e isola alguma qualidade essencial de cada um deles que pertence a uma categoria genérica" (LURIA, 1990, p. 113-114).

0 Quadro 8 traz as respostas da primeira participante. Ainda que cotidianamente as pessoas lidem com situações que envolvem hospital e escola, é possível acompanhar que a participante forneceu um conceito avaliado como científico para hospital ao dizer que se trata de área de saúde, ao invés de descrever operações que normalmente têm lugar nesses ambientes, o que aconteceu com a maioria das respostas para esse conceito fornecidas pelas participantes subsequentes.

Portanto, nesse caso, a participante conceituou em termos teóricos, e não práticos. Nesse sentido, considerou-se que, ao definir democracia, ela formulou uma definição prática, com um caráter prescritivo, o que levou as autoras deste artigo a discordar que se tratasse de uma conceituação com estrutura científica, que foi a opinião do grupo.

Quadro 8 - Respostas fornecidas pela participante A201

\begin{tabular}{|c|c|c|}
\hline 0 que é... & Resposta & ECP \\
\hline 1. um hospital? & Área própria de saúde. & Científico \\
\hline $\begin{array}{l}\text { 2. proteção } \\
\text { ambiental? }\end{array}$ & $\begin{array}{l}\text { Cuidar bem, limpar bem. Se for } \\
\text { entre filhos é saber dar carinho, } \\
\text { saber conversar. }\end{array}$ & Cotidiano \\
\hline $\begin{array}{l}\text { 3. uma } \\
\text { democracia? }\end{array}$ & $\begin{array}{l}\text { Deveres que o político } \\
\text { devia cumprir, de acordo } \\
\text { com o que promete. }\end{array}$ & Científico \\
\hline $\begin{array}{l}\text { 4. dependência de } \\
\text { drogas? }\end{array}$ & $\begin{array}{l}\text { Usar drogas sem querer parar, } \\
\text { continuamente, aumentando a } \\
\text { cada dia }\end{array}$ & Cotidiano \\
\hline 5. uma escola? & $\begin{array}{l}\text { É a coisa mais importante para o } \\
\text { ensino e para a educação. }\end{array}$ & Cotidiano \\
\hline 6. reforma social? & $\begin{array}{l}\text { Quando os políticos querem } \\
\text { mudar alguma coisa, reformar } \\
\text { alguma coisa, como hospital, } \\
\text { fila do SUS. }\end{array}$ & Cotidiano \\
\hline
\end{tabular}

Fonte: Dados da pesquisa

No Quadro 9, constam as respostas para a primeira participante semianalfabeta.
Quadro 9 - Respostas fornecidas pela participante F234

\begin{tabular}{|c|c|c|}
\hline 0 que é... & Resposta & ECP \\
\hline 1. um hospital? & Problema (Valor ausente). & Cotidiano \\
\hline 2. proteção ambiental? & $\begin{array}{l}\text { Pessoas para cuidar tanto } \\
\text { dos animais quanto da } \\
\text { natureza. }\end{array}$ & Cotidiano \\
\hline 3. uma democracia? & $\begin{array}{l}\text { Devemos ter políticos mais } \\
\text { responsáveis que pensem } \\
\text { nas pessoas e não só neles } \\
\text { mesmos. }\end{array}$ & Cotidiano \\
\hline $\begin{array}{l}\text { 4. dependência de } \\
\text { drogas? }\end{array}$ & $\begin{array}{l}\text { Jovens se destruindo com } \\
\text { produtos químicos. }\end{array}$ & Cotidiano \\
\hline 5. uma escola? & $\begin{array}{l}\text { Forma de educar, } \\
\text { aprender profissão. }\end{array}$ & Científico \\
\hline 6. reforma social? & $\begin{array}{l}\text { Plano de saúde bom } \\
\text { para pessoas carentes, } \\
\text { escolaridade melhor. }\end{array}$ & Cotidiano \\
\hline
\end{tabular}

Fonte: Dados da pesquisa

Por fim, apresentam-se as respostas da última participante do subgrupo, detalhadas no Quadro 10. É possível acompanhar que suas conceituações, na sua maioria classificadas como possuidoras de estrutura científica, revelam que a participante lida com as palavras de um modo mais hierarquizado, com destaque para as respostas fornecidas para escola e reforma social.

Quadro 10 - Respostas fornecidas pela participante F246

\begin{tabular}{|c|c|c|}
\hline 0 que é... & Resposta & ECP \\
\hline 1. um hospital? & $\begin{array}{l}\text { Pra quem vai deve ser ruim. } \\
\text { Pra pessoa ver como é que } \\
\text { tá a saúde e tratar. }\end{array}$ & Cotidiano \\
\hline $\begin{array}{l}\text { 2. proteção } \\
\text { ambiental? }\end{array}$ & $\begin{array}{l}\text { É para manter o equilíbrio } \\
\text { na terra. }\end{array}$ & Científico \\
\hline $\begin{array}{l}\text { 3. uma } \\
\text { democracia? }\end{array}$ & É o direito do povo. & Científico \\
\hline $\begin{array}{l}\text { 4. dependência } \\
\text { de drogas? }\end{array}$ & $\begin{array}{l}\text { É o desiquilíbrio mental. A } \\
\text { pessoa não ter autocontrole. } \\
\text { [sic] }\end{array}$ & Científico \\
\hline 5. uma escola? & A base de tudo. & Científico \\
\hline $\begin{array}{l}\text { 6. reforma } \\
\text { social? }\end{array}$ & É evolução. & Científico \\
\hline
\end{tabular}

Fonte: Dados da pesquisa

Ao iniciar a presente seção, apresentam-se os termos de acordo com os quais foi organizada 
a proposta de buscar indícios de letramento na oralidade de adultos não escolarizados. Uma vez analisados os conceitos formulados por três das participantes com estrutura do significado da palavra mista, julgou-se ter encontrado tais indícios. Foi possível concluir, a partir da maneira como as participantes resolveram as tarefas propostas, que algumas das produções orais exibiam as características do pensamento científico.

Oliveira escreveu que analfabetos na sociedade letrada são personagens que vivem em cidades que se caracterizam por ser escolarizadas e industrializadas, sem dominar completamente o sistema simbólico da escrita. A pesquisadora concorda com os autores da perspectiva do letramento, que defendem a ideia de que devem ser considerados "graus de analfabetismo", ou de que não existe grau zero de letramento em sociedades letradas, uma vez que esses adultos, ao viver nelas, são progressivamente “[...] contaminados pelas informações desse mundo e acumulam conhecimentos sobre suas regras de funcionamento e sobre o próprio sistema de escrita" (OLIVEIRA, 1992, p. 1).

$\mathrm{Na}$ descrição que se acaba de apresentar, constatou-se que, ainda que o ambiente privilegiado para lidar com os objetos em termos de categorias taxonômicas supraordenadas seja a escola, pelo menos em certo nível, foi possível para esses participantes exibir um desenvolvimento que emula o padrão fomentado pela escolarização.

\section{Síntese para os três grupos de tarefas}

Para a tarefa de indicação do terceiro redundante, foi predominante o princípio de agrupamento baseado em uma situação prática. Na maioria das respostas, foram recolhidos exemplos de observações cotidianas: foi descrito o funcionamento conjunto dos objetos das tarefas; preferências pessoais, idiossincráticas, foram utilizadas para justificar as respostas fornecidas.

Em relação à tarefa de detecção de semelhança, muitos participantes negaram que existisse uma semelhança, ou a indicaram baseando-se em critérios sensorialmente baseados; outros apontaram diferenças ao invés do que foi pedido na tarefa.

No caso da tarefa de definição de conceitos, de modo geral, os participantes demonstraram dificuldade em formular conceitos abstratos, como é o caso da pergunta sobre reforma social. Em alguns casos, os participantes forneceram julgamentos morais, como no caso da pergunta sobre dependência de drogas: "É errado, é ruim". Para os conceitos mais comuns no cotidiano das pessoas, como hospital, houve uma tendência de conceituação em termos de uma descrição do funcionamento da instituição.

Em relação aos dois modos de utilização da linguagem, a estrutura do significado da palavra do tipo predominantemente cotidiana foi encontrada em maior número nas respostas dos participantes que, para formular seus conceitos, basearam-se principalmente em impressões imediatas da vida cotidiana. Suas produções foram estreitamente vinculadas às suas próprias experiências, o que produziu como resultado uma extrema variedade de conceitos, quase singulares. Esse resultado se coaduna com os achados de outras pesquisas dessa natureza (LURIA, 1990; SALOMÃO; TOOMELA, 2010; TOOMELA, 2003).

Os autores da perspectiva do letramento destacam a importância do conhecimento pragmático do funcionamento do discurso letrado, e sugerem que esse domínio pode ser uma alternativa, no sentido de que, nas sociedades letradas, diversos sistemas de conhecimento competem com aqueles adquiridos através da escolarização formal (KLEIMAN, 2001, 2002, 2007; PEREIRA, 1998; TERZI, 2003; TFOUNI, 2006; VÓVIO, 2007).

Através das respostas desses participantes, observamos que frequentar a escola, ainda que por poucos anos, possibilita o início do desenvolvimento de uma forma padronizada de conceituação. 0 modo de operação proposto pelo ensino 
formal, escolar, coloca as pessoas em contato com essa estrutura de organização conceitual, possibilitando o salto qualitativo no pensamento verbal que nos leva a ter consciência do pensamento, e das regras de funcionamento do pensamento - estrutura do silogismo, metacognição (LURIA, 1990; VIGOTSKI, 2009; TOOMELA, 2003).

A esse respeito, Oliveira (1992) escreveu sobre dominar a lógica do mundo letrado. Toomela (2003) discutiu a consciência metalinguística, no sentido de desenvolver a capacidade de pensar sobre o pensamento. É nesse ponto que se situa a nossa discordância com relação aos autores da perspectiva do letramento, que defendem que um domínio da pragmática de funcionamento do discurso, exibido quando o adulto não escolarizado que vive na sociedade letrada emula o discurso letrado, pode ser um caminho alternativo. Entendemos que a questão não é sobre se o discurso é utilizado, mas sobre como, no sentido de que aplicar a regra é diferente de saber a regra.

\section{Consideraçōes finais}

Como ponto importante para estas considerações, retoma-se o objetivo geral deste estudo, que consistiu em caracterizar, analisar e discutir as relações entre o grau de escolaridade (não alfabetizado, semianalfabeto) e a estrutura conceitual (predominantemente cotidiana ou científica) na amostra de participantes. A questão da possibilidade de desenvolvimento de um padrão letrado na oralidade de adultos não escolarizados foi abordada a partir da análise do grau em que desenvolver atividades cotidianas, sem completar os ciclos formais de escolarização, possibilitou aos participantes da pesquisa desenvolver um padrão que assumimos como letrado na oralidade.

No presente estudo, realizamos uma descrição que estabelece, ao lado de tantas outras, a importância do processo de escolarização, que se converteu em um espaço fundamental de desenvolvimento na imensa maioria das sociedades humanas e do qual muitas pessoas ainda não participam. Os adultos não escolarizados desta pesquisa exibiram uma modalidade de pensamento que, em termos desenvolvimentais, ainda não os coloca em condição de utilizar as formas mais sofisticadas de desenvolvimento do pensamento humano.

Examinaram-se detalhadamente as produções dos participantes que formularam mais conceitos científicos, em busca de indícios de oralidade letrada. Esse foi o ponto principal que se elegeu para realizar a discussão, dado que encontrar tais indícios permitiria discutir, sob inspiração dos autores da perspectiva do letramento, alguns postulados da psicologia histórico-cultural. 0 interesse foi investigar se e como acontece alguma novidade no fenômeno em estudo. A novidade, no presente estudo, é que uma parte dos participantes permanece não escolarizada, vivendo seu cotidiano nas cidades e não em relativo isolamento, como os camponeses da pesquisa de Vigotski e Luria (LURIA, 1990).

Os autores da perspectiva do letramento argumentam que, nas sociedades letradas, não existe um grau zero de letramento, por causa das atividades letradas cotidianas nas quais as pessoas se veem envolvidas, dominem ou não as habilidades de leitura e escrita. As autoras do presente estudo concordam apenas em parte com essa assertiva. Isso porque, devido à institucionalização, na escola, do treinamento em operações teóricas, esse contexto ainda aparece como privilegiado para propiciar esse tipo de desenvolvimento. Conclui-se, assim, que não participar da escolarização formal significa, para um grande contingente de pessoas, não desenvolver as modalidades mais hierárquicas de operação do pensamento. 


\section{Referências}

BROCKMEIER, Jens; OLSON, David. Introduction: what is a culture of literacy? In: BROCKMEIER, Jens; WANG, Min; OLSON, David (Org.). Literacy, narrative and culture. Richmond: Curzon, 2002. p. 1-14.

KLEIMAN, Angela Bustos. Alfabetização e letramento: implicações para o ensino. Revista da FACED, Salvador, n. 6, p. 99-112, 2002.

KLEIMAN, Angela Bustos. Letramento e suas implicações para o ensino de língua materna. Signo, Santa Cruz do Sul, v. 32, n. 53, p. 1-25, dez. 2007.

KLEIMAN, Angela Bustos. Programas de educação de jovens e adultos e pesquisa acadêmica: a contribuição dos estudos do letramento. Educação e Pesquisa, São Paulo, v. 27, n. 2, p. 267-281, jul./dez. 2001.

LURIA, Alexander Romanovich. Desenvolvimento cognitivo: seus fundamentos culturais e sociais. São Paulo: Ícone, 1990.

OLIVEIRA, Marta Kohl de. Analfabetos na sociedade letrada: diferenças culturais e modos de pensamento. Travessia, São Paulo, v. 5, n. 12, p. 17-20, jan./abr. 1992.

OLIVEIRA, Marta Kohl de. Escolarização e desenvolvimento do pensamento: a contribuição da psicologia histórico-cultural. Revista Diálogo Educacional, Curitiba, v. 4, n. 10, p. 23-34, set./dez. 2003.

PEREIRA, Ivani Aparecida. A oralidade letrada de lideranças não escolarizadas. 1998. Tese (Doutorado em Ciências) Universidade Estadual de Campinas - Unicamp, Campinas, SP, 1998.

SALOMÃO, Soraya; TOOMELA, Aaro (Org.). Literate mentality: less constraints and more universality. In: International Conference on the Dialogical Self, 6., 2010, Athens. Guiding the dialogue: constraining the dialogical self. Panel for the... Athens: [s. n.], 2010.

TERZI, Sylvia Bueno. Afinal, para quê ensinar a língua escrita? A formação do cidadão letrado. Revista da FACED, Salvador, n. 7 , p. 227-240, 2003.

TFOUNI, Leda Verdiani. Adultos não-alfabetizados em uma sociedade letrada. São Paulo: Cortez, 2006.

TOOMELA, Aaro. Relationship between personality structure, structure of word meaning, and cognitive ability: a study of cultural mechanisms of personality. Journal of Personality and Social Psychology, Washington, v. 85, n. 4, p. 723-735, oct. 2003.

VAN DER VEER, Rene; VALSINER, Jaan. Vygotsky: uma síntese. São Paulo: Loyola, 1996.

VIGOTSKI, Lev Semenovich. A construção do pensamento e da linguagem. São Paulo: Martins Fontes, 2009.

VÓVIO, Claudia Lemos. Entre discursos: sentidos, práticas e identidades leitoras de alfabetizadores de jovens e adultos. 2007. Tese (Doutorado) - Universidade Estadual de Campinas - Unicamp, Campinas, SP, 2007.

Recebido em: 12.02.2014

Aprovado em: 23.09.2014

Delma Barros Filho é doutoranda em psicologia do desenvolvimento pela Universidade Federal da Bahia (UFBA), bolsista CAPES. Graduada em psicologia pela UFBA e membro do Núcleo de Estudos sobre Desenvolvimento e Contextos Culturais, vinculado ao Conselho Nacional de Desenvolvimento Científico e Tecnológico (CNPq).

Ana Cecília de Sousa Bastos é docente dos programas de pós-graduação em psicologia, na Universidade Federal da Bahia, e em família na sociedade contemporânea, na Universidade Católica do Salvador. É doutora em psicologia pela Universidade de Brasília (UNB) e pesquisadora I-D, CNPq. 